\title{
Permanent transience: the identity crisis within representations of new urban housing
}

\author{
A. Evans \\ School of Art, Design and Fashion, University of Central Lancashire, UK
}

\begin{abstract}
In the twenty-first century, our way of life is rapidly accelerating. This acceleration can be attributed to a disposable and transient lifestyle, the desire to consume and the accessibility of products, all of which are simultaneously dependent on one another. Rarely, however, do we consider the notion of the disposable and the dynamics of consumption and production in spatial terms. In 2007-2008, during the last economic boom in the UK, house building peaked as 207,370 new homes were constructed compared to 128,680 in 2009-2010 after the economic collapse (Housing and Planning statistics 2010), demonstrating the relationship between the economy and construction, and in turn, production and consumption. This paper considers three key urban issues related to the disposable and transient, production and consumption, and the identity of dwelling. The paper explores issues in housing production to raise concerns of social and community sustainability within capitalist urbanisation of cities. This exploration is carried out through two case studies of different typology, analysed via on-site interviews and discussions with residents. Both case studies were initiated during the last decade, these being Bellevue, Dublin - a large apartment complex on the outskirts of the city centre, and Cranbrook, Exeter - a new suburb to support Exeter's expanding city (still under construction at the time of writing). The paper then continues by espousing Paul Virilio's theories of the dromosphere and picnolepsy, and drawing key observations from the case studies interrogates the relationship between speed, the disposable consumable and identity within housing. The paper contests the concept of dwelling as mass product, arguing that the consumeristdriven catalogue browsing approach to home ownership by definition separates the very essence of dwelling from community. In conclusion, this paper attests that slow urbanism, achieved by critical reframing of production, consumption and identity within existing and future communities could successfully improve social sustainability in the thickening urban network of globally connected cities.
\end{abstract}


Keywords: socio-cultural identity, housing identity, slow urbanism, spatial production, spatial consumption.

\section{Introduction}

The patterns of life have accelerated exponentially during the past two decades, and these accelerations are clearly visible through the acquisition, use, exchange and disposability of products, which are particularly evident within digitally fuelled consumer culture. The physical scale of product acceleration is variable and is openly represented via the micro and small scale of SIM cards, smartphones, and laptops to the medium scale of private vehicles. This acceleration can be attributed to an increasingly disposable, transient and nomadic lifestyle, the desire to consume, the accessibility of products, the ease of gaining credit, the relentless advertising and consumer pressure driven by capitalist consumer culture, all of which are simultaneously dependent on one another.

However, when these products are observed through the larger scale representations of dwelling houses, there is a disparate attitude to the spatiodomesticity of the house within the system of objects of the contemporary western world. Whilst during the late 1990s publications such as Mitchell's City of Bits speculated about the future of the digital world in terms of urban space and architecture, the issue of the globalisation of domestic space was ignored in favour of the excitement of city space and the information superhighway [1]. Throughout much of the contemporary world it is commonplace to notice a new car, its form sleekly designed to celebrate the speed of contemporary living, complete with computer navigation parked in a driveway of a new dwelling adorned with pastiche architectural tropes, but what does this mean in terms of the disposable, transient and permanence, production and consumption, and the identity of dwelling? Furthermore, what are the implications of these vis-à-vis the sustainability of global housing?

Paul Virilio discusses the ideas of the dromosphere and picnolepsy in relation to the city and city life $[2,3]$. The dromosphere, he suggests, is that sphere within the evolution of human life where speed inevitably causes the accident and furthermore, these accidents occur before humankind are aware they have happened. He continues to philosophise on the point that any invention or development in the way of human life creates contexts and situations for accidents. Picnolepsy, Virilio argues is almost an epileptic consciousness generated by the perceived speed and immediacy of the world within which one is at a particular moment. Both dromosphere and picnolepsy as cultural cause and human experience are critical to the discussion here concerning global dwelling. By developing a theoretical framework based on dromosphere and picnolepsy in parallel with case study inquiry, this paper aims to make sense of the disparate attitudes to dwelling, sustaining community and acceleration of life and calls for an urgent shift in attitude to the representation and identity of the dwelling for a sustainable post-global future. Furthermore, it seeks to position itself with an approach to the future of sustainable dwelling that supports and challenges the demands of contemporary and future life globally. 


\section{Case studies}

The case studies selected were both conceived during the last decade - Bellevue, Islandbridge, Dublin, Ireland (completed 2006) and Cranbrook, Exeter, Devon, UK (phase one completed 2012, total completion due 2027). Both sought to solve, to differing degrees, the housing shortage in the expanding cities of Dublin and Exeter, and additionally to contribute to a stimulating regional and national economy. These case studies were selected as they represent the two ends of the architectural spectrum for conventional western mass housing typologies at the beginning of the twenty-first century - the contemporary urban apartment block and the suburban low-rise estate neighbourhood. In terms of their architectonic identity, they are also at opposing ends of style. Bellevue attempts to capture some sense of a slick, trendy urban lifestyle through its use of minimal detail, external render, brickwork and uniformed floor layouts, whilst Cranbrook's aesthetic is wholeheartedly one of pastiche, incorporating elemental and detail references from Victorian, Georgian, Edwardian and Tudor eras within a conventional 1960s housing estate layout. Additional to these architectural qualities, the case studies were also selected based on the majority demographic of their inhabitants, further explained in the methodology sub-section below.

\subsection{Methodology}

The methodology for analysing these case studies used a combination of literature review and desktop research coupled with photographic survey and qualitative and quantitative interviews with residents, the latter both conducted on site by the author. 20 households from each case study were invited to interview, with 12 positive responses at Bellevue and 14 positive responses at Cranbrook. The original households comprised a total of 57 occupiers (including children) at Bellevue and 61 at Cranbrook.

The demographic targeted were made up of young professionals, within the age group 28-42. Within both case studies this group of people determine 89 percent of the occupied dwellings. All participants of interviews were also aged 28-42, and were either single (20 percent of interviewees), married or in a partnership (80 percent of interviewees), and all (except one couple) had children under the age of 12.76 percent were home owners with mortgages and 24 percent were renting with a view to buy property by 2020 . All interviewees had lived on site for less than 36 months. This demographic was also selected as they were all avid users of contemporary technology, and all owned at least four, and in three cases as many as eleven internet enabled devices in their homes (laptops, tablets and smartphones) and all owned at least one car produced within the last 8 years, which strongly evidenced them as definite consumers of the accelerating world.

Participants were interviewed at their homes, which supported the collection of more thorough and realistic sets of qualitative as well as quantitative data as participants were able to demonstrate the context of their responses visually, materially, spatially and culturally. All participants were asked the same set of questions, designed to generate conversation about identity, consumption and 
permanence. Complete discussions were audio recorded for post-interview analysis, and key parts of dialogue were then extracted for use in the two subsections below. These methodological parameters and procedures were critical to enable collected data to be as useful as possible when addressing the questions of identity, disposability and permanence within the context of dwelling in an accelerating world.

\subsection{Case study 1: Bellevue, Islandbridge, Dublin, Ireland}

Bellevue, Islandbridge is a large, medium-rise private developer-led housing project in Dublin, Ireland, built in the last economic boom. The estate contains a collection of 1,2 and 3 bedroom apartments, which are arranged around an artificial pond and have access to an underground car park. It is located between Phoenix Park and Memorial Park to the west of the city's boundaries. The render and brick contemporary blocks range between four and five storeys high, and whilst not enormous are considerable in scale for suburban Dublin. All apartments are inhabited, although this is not apparent from the outside as there is no public space offered to socialize or meet (Figure 1). There are no benches overlooking the lake, no walls to lean on, and nowhere to talk to friends or neighbours. To the east of the complex of buildings between the canal and the River Liffey lies a very promising garden, however occupation of this space is not promoted.

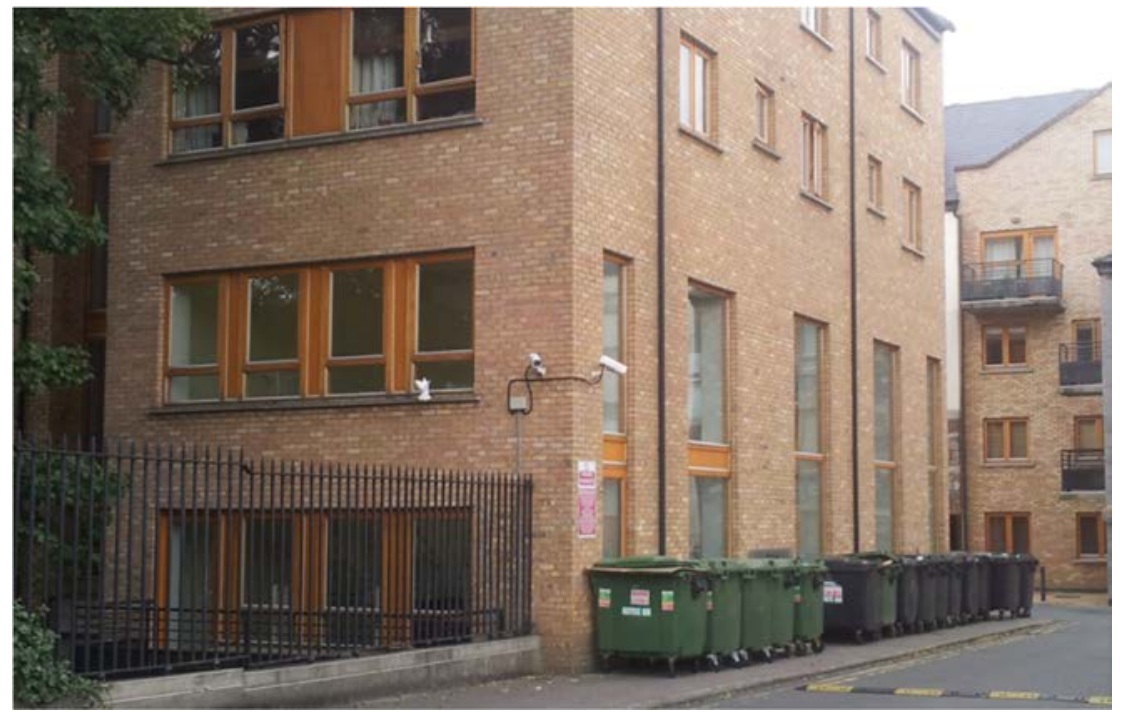

Figure 1: A typical street view at Bellevue, Islandbridge.

Whilst the number of young professionals that these types of dwelling are built to attract is increasing in Dublin, displaced growth, depopulation and outmigration in rural areas of Ireland [4], as well as the relocation of city inhabitants to the suburbs, are still pressing issues. To those outside Islandbridge, Bellevue 
represents successful contemporary housing, but when one examines Bellevue through personal experience and interviews with inhabitants the vacant social life of the place becomes revealing.

A consequence of the unsatisfactory outdoor space is the increase in warning signage and CCTV, further reinforced by the circulation strategy, which enables one to drive into the underground, hidden car park and enter an elevator straight to one's apartment without even having to use the front door of the building. One resident mentioned that they rarely see anybody, and when they do their paths cross with a brief greeting or with no acknowledgement at all:

Well, now I never see anyone, I've been here three years, just my brother who is the postman. He knows more people than me! Maybe I should go and deliver all the letters.

Another resident described the feeling of seclusion they experienced at three moments, firstly when approaching the complex as a whole, as one drives through the gates to the car park, secondly as one leaves the car and travels to the front door of the apartment, and finally when one is actually dwelling inside the apartment:

Sometimes it is quite scary, I come home in the dark when it's winter, you know, you hear about people getting attacked in car parks. I know this is meant to be safe, but it can be really unnerving and you feel really alone.

It was clear that a sense of disconnection was experienced by these residents. When residents were asked about the identity of Bellevue, the conversations shifted to the identity of Dublin as a city, and residents did not view Bellevue as having an identity of its own:

I think....identity, well, Dublin has a great identity, although everyone thinks all we do is drink Guinness all day, haha. But no, I don't think there is an identity here, how can there be, nobody uses any of the outside, it's just blocks. Nice blocks, but just blocks.

Furthermore, one resident began to talk about their possessions:

My identity is in my things and clothes. I can't show that in an apartment, can I? I mean, in the inside, but outside, that's what happens in flats.

Several residents mentioned that it was disappointing that there were no amenities close by, the nearest shops being located on Emmet Road some twenty minutes' walk away:

There's no shops nearby, I don't have a car and I have to walk right up and over the hill above, we could do with a shop or two here. Perhaps that would get a few people along and chatting, maybe if we made friends we would identify with each other. 
What begins to become evident here at Bellevue is that the developers have constructed a functional project that is one which deals with pure pragmatics and exists as a spatial solution to a housing need. It appears through the interviews and analysis of the project's resolution that, at best, assumptions have been made by the developers that inhabitants would be car owners, use the circulation strategy via the car park, and experience the external space solely as a view rather than an inhabitable space. When asked about permanence, all residents interviewed, with the exception of one, had decided since occupying their apartment to move sooner than they had originally agreed:

Well, it is no place to bring up kids, they get bored to tears. I'm actually beginning to dread weekends, because it means loading the car up and going to the centre or something. There's not anywhere for them here, see. They usually end up on the internet or playing internet games. Thank God for the internet!

Another resident drew an insightful comment about how they perceived Bellevue before and after they moved in:

It looked pretty dreamy when we first saw it, it was new and we were very enthusiastic about the parks and gardens. As it happens, we don't use them, it's almost an impossible task even to walk around them. Trouble is, it looks like all the other new flats now.

As consumers of space, all the residents interviewed vocalised that they had bought their apartment based on the idea of clean, contemporary living. They had been convinced that the apartments would be spacious and offer support for their way of life, but were disappointed that once they had experienced living in them, their prior anticipation of some kind of permanence had become replaced with the disposable.

\subsection{Case study 2: Cranbrook, Exeter, Devon, UK}

Cranbrook is the larger of the two case studies, and is a new district currently under construction in Devon, UK, to support the increased need for housing and overspill from the city of Exeter. Its inception follows Devon's 2001-2016 Structure Plan [5], and East Devon's Local Plan 1995-2001 [6]. Cranbrook currently has a population of 2,200 and is proposed to provide over 6,500 residential properties by 2027 . Completed amenities and services include a new railway station on the Exeter to London Waterloo line (opened 2015), St. Martin's primary school and The Younghayes Centre as a meeting point for community groups and clubs, all serving the completed phase of the development. There are also new retail outlets servicing phase one, and although these amenities and community spaces provide more than Bellevue, what is interesting about the comments from interviewees here is their attitude to permanence (Figure 2). 


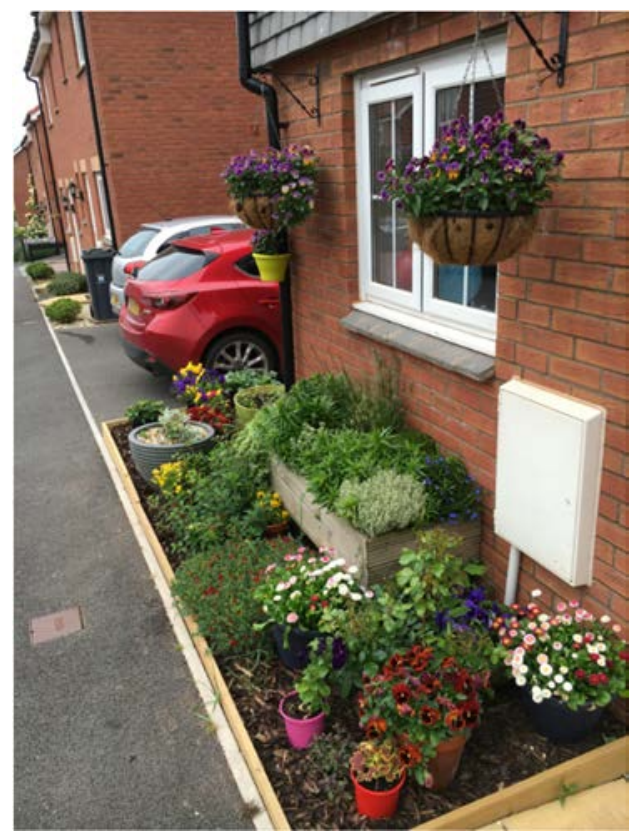

Figure 2: One interviewee's front garden at Cranbrook.

Living here is not a long-term position, we are currently in the process of sourcing a new mortgage and are looking to a more rural setting so that we can be more self-sufficient, as we enjoy gardening and growing plants. We take a great pride in our front garden, and other residents say it is the best one in our street. We have a small back garden, but have crammed a lot of vegetables and fruits within it. We are not keen on being overlooked by neighbours when in our garden. Another reason for moving is our pets. We have 3 dogs and 2 cats, and we live on a busy road, so the worry about them getting run over is always there.

Perhaps the highest uncertainty in responses gathered from the interviews still had a seed of doubt with regards to permanently living in Cranbrook:

Cranbrook has certainly given my family and I an opportunity to own our first house, and a lovely house it is, as it is still standing, but whether it is one we are in for the long haul, I am not convinced yet.

Others expressed cautiousness about moving to a new town build entirely from the ground up:

Cranbrook as a whole is just frustrating to myself at present and this is generally down to the developers who seem not to finish a job before moving on to the next, whether that be finishing a house, don't even get me started there, or laying a paving slab or area of greenery. 


\section{Another commented:}

I have been here for two years now and phase 1 is still far from finished. I think they are now building phase 3. No one seems to want to take responsibility for their shortcomings and all seem to pass the blame onto other companies or local councils.

Another concerning observation is that although the amenities and shops have been completed for less than a couple of years, they are already beginning to fall into disrepair:

All the developers seem interested in is building houses as, I guess, this is where the money is for them. We currently have a Co-op, Chinese take away, estate agent, random, pharmacy and a charity shop, great choice again, along with a couple of parks which seem to be slowly getting destroyed, perhaps by some frustrated teenagers? When and where is the apparent high street going to be built and what sort of shops/amenities can we expect, perhaps some tattoo parlours and vapour shops, again sorry, sounds like I've turned into a proper snob.

It is possible that the timeline of the build programme for Cranbrook was poorly considered with little regard to the processes of occupation and inhabitation, and at such an early stage in the construction of this new town, the opportunity to build a cohesive social and community structure for the future appears to have been missed.

When asked about the identity of Cranbrook, interviewees were varied in their responses as some viewed Cranbrook as a whole, connecting the idea of identity with physical appearance (Figure 3):

Cranbrook is going to be a big town. It looks like most other housing estates, I suppose it is meant to, it is familiar I guess.

Others viewed what living in Cranbrook meant to them personally:

Honestly, I don't think that Cranbrook has an identity for me. I just think of it as where I live, for now, which is a bit of a shame. The houses are meant to be eco-friendly, reducing the heat bill. It's good that the water and heating all come from one supplier.

A more detailed response draws a direct comparison with older traditional housing stock:

The houses kind of remind me of older towns, there's a mixture of houses, some look like terrace houses and some look like estates. I think they look alright, maybe in a few years they will look better, as they get weathered. There are lots of different types but some of the gardens are a weird shape and that's because they've just crammed the houses in, some are meant to 
be detached but they are so close to the neighbour it is silly. I don't know why they didn't just join them up.

Finally, this interviewee commented on the pace of life:

The doors and windows are small; they are trying to look like cottages. What good is a cottage these days, when you have kids, internet, and whatever, life is too fast for living like we are in the nineteenth century! I don't see why it has to try to look old.

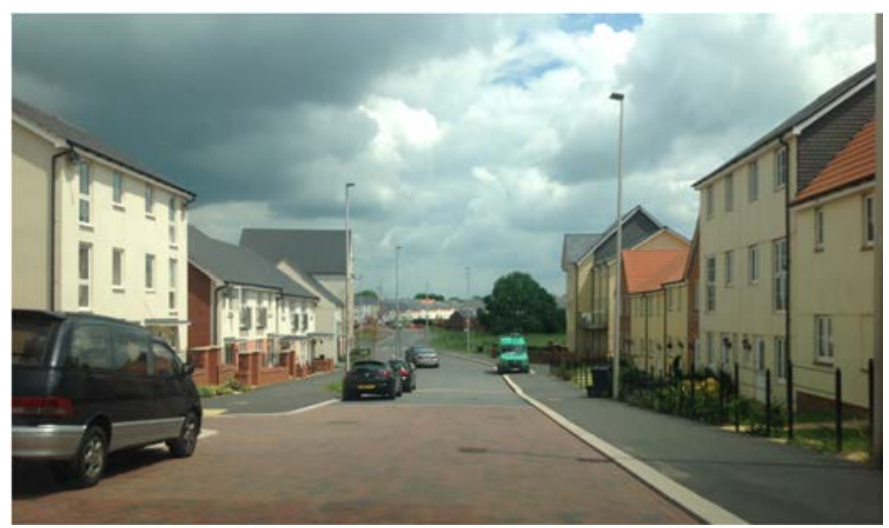

Figure 3: Attempted variety in the housing stock at Cranbrook.

\section{Accelerated urbanism and the generics of housing}

There is something of an identity crisis within the accelerated architecture of dwellings. In mainstream housing stock and supply, what coexist are two major approaches to housing solutions, neither of which address contemporary life nor will address future life successfully. On one hand is the contemporary language of high and medium-rise city apartment living such as Bellevue, which suggest a clean, urban form of living appropriate to the contemporary city and alludes to a successful future. On the other hand, there are the housing estates and developments comprising of low-rise, traditional yet historically varying styles produced with a pastiche attitude, represented clearly at Cranbrook. These design approaches share two important phenomena - speculation and conservation. They are speculative in that their provision of space is derived purely from economics, if the figures work, the project moves forward. Secondly, and equally as alarming, is that the physical forms these projects exist under are conservative, conventional and ignore the challenges of contemporary life.

\subsection{The static and fluidity of identity}

In Véhiculaire (Virilio, 1976) a question arises: "what will we wait for when we no longer need to wait to arrive?" [7]. Directing this question to the crisis of 
housing, we need to question the relevance of the housing stock that is built. To build and construct is to remain busy, during the most recent economic expansion we witnessed much construction, from public space to private houses. But what is truly embodied within the spectacular actions of building? Surely there is cause for concern about the nature of what is on offer when residents of new housing stock are confused by their own neighbourhood.

The house building industry is suffering an architectural identity crisis resulting from its attempts to maintain momentum in the accelerating economic, and so it builds fast and cheap, yet seeks reassurance that its solutions are appropriate by building the familiarity of the generic contemporary or the nostalgia of the historic. The tragedy lies in the success of the economic, and the inherent problem within this agenda is that the dwellings become by-products of economic actions. If within three years of occupation residents are uncertain of the homes they occupy, there must be a sea-change. As one interviewee voiced:

I don't know why I bought this place, what does it even mean?

\subsection{Speed of productivity and the pressure to consume}

Accepting that in the contemporary western world capitalist-led consumption drives mainstream life; how can the representational value attached to dwellings be considered through the lens of a certain picnolepsy? A particular consciousness is invented when life becomes devoid of speed. This picnoleptic consciousness, Virilio claims, is constructed of the gaps and glitches that fill the voids left when our understanding of speed disappears [3]. As humans, we are taught that to reflect on life supports learning and progression. Reflection often takes place within a static space, ritualistically and habitually the home space, so here, the picnoleptic experience occurs in the home. We oscillate between a reflective picnoleptic state and the pressures of the dromosphere, and our resulting actions conspire to generate a cultural comfort in consuming the new yet familiar. If this context is applied to production, it may be that a reflective and critically informed praxis can be developed to produce housing solutions that are mediators of the picnoleptic and the dromosphere and furthermore offer some form of contextual identity for their occupants.

\section{Conclusions}

The global future of dwelling ruires a significant socio-cultural shift in attitude. As a matter of urgency, the current actions of the house building industry must be reviewed and informed judgements must be made on issues such as representation and identity, production and consumption, and disposability and permanence. Furthermore, effective strategies to position house building within the system of objects in the future world must be devised.

The future of housing may support two dynamics of space, interrelated yet different in experience. The first might be those spaces which complement and become part of the dromosphere, spaces which embrace and attempt to work with 
the patterns of the more complex invisibility of speed since the arrival of the digital age and the internet. Architecture needs to be in a powerful position here, as the technological construct of the city, within, of course, the global and post-global world, has become saturated with this invisibility of speed. The architecture of future dwellings may expose, challenge, celebrate or enhance this saturation and by such begin to make sense of the architecture of the dwelling.

An alternative take is to capture the essence of the picnoleptic experience. By seizing the gaps and glitches generated by our disconnection from the speed of multi-dimensional digital life and recalibrating our physical three- and fourdimensional life, opportunities arise for living spaces which negotiate between these gaps and glitches. These negotiations may manifest themselves physically; spaces might offer respite from the invisibility of speed, they may support speed and acceleration but from a distance, offering spaces of slow occupation to empower and sustain growth. The counter-narrative of procuring and nurturing garden baskets at Cranbrook, the feeling of danger walking to one's flat at night, the dismay at houses attempting to look old all allude to a similar direction - the house building industry must talk to its consumers.

Whether parties involved with the construction of dwellings fully embrace speed and acceleration (both invisible and visible) or develop housing as a haven for recuperation from the dromosphere, the techniques of construction and the structure of the house building industry cannot afford to continue to perform in an obsolete way. It seems very clear that in a global and post-global world, the networks of cities connected through satellization and the thermosphere, need to search for new ways to exhibit identity and build community attitude and social sustainability.

Finally, this paper has drawn on the conventional structure of the house building industry and its consumers, and it is critical at this point to acknowledge the alternative and flexible housing solutions by practitioners such as Lo-Fi Architecture and Alejandro Aravena's do-tank Elemental strive to address the speed and immediacy of the city, working with communities to construct appropriate and responsible architectural identity. There is a growing amount of exemplary practice of this nature, but sadly, these kinds of projects are a miniscule percentage of the housing market. If the future of dwelling is to be sustained and maintained in alignment with the development of the digital world, housing solutions must navigate and negotiate space within the construct of the dromosphere.

\section{References}

[1] Mitchell, W.J., City of Bits: Space, Place, and the Infobahn, MIT Press: Massachusetts, 1995.

[2] Virilio, P., Speed and Politics, Semiotext(e) Foreign Agents, MIT Press: Massachusetts, 2006.

[3] Virilio, P., Negative Horizon, Continuum Impacts: London, 2008. 
14 Global Dwelling: Approaches to Sustainability, Design and Participation

[4] Daly, G. \& Kitchin, R., Shrink smarter? Planning for spatial selectivity in population growth in Ireland. Administration, 60(3), pp. 159-186, 2013. http://eprintsprod.nuim.ie/4509/1/RK_Shrink.pdf.

[5] Devon County Council, Structure plan 2001 to 2016. www.devon.gov.uk/ structure_plan_2001_to_2016.htm. Accessed on: 12 Apr. 2016.

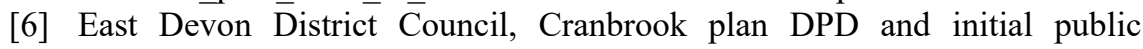
consultation. http://eastdevon.gov.uk/planning/planning-policy/cranbrookplan/the-cranbrook-plan-dpd-and-initial-public-consultation/\#articlecontent. Accessed on: 28 Feb. 2016.

[7] Virilio, P., Véhiculaire. L’insécurité du territoire, ed. P. Virilio, Editions Galilée: Paris, pp. 243-269, 1976. 